\title{
GEOPHYSICAL PARAMETER RETRIEVAL FOR MICROWAVE C BAND SYNTHETIC APERTURE RADAR (SAR) DATASET USING INTEGRAL EQUATION MODEL
}

\author{
S. B. Sayyad ${ }^{1 *}$, M. A. Shaikh ${ }^{2}$, S. B. Kolhe ${ }^{3}$, P. W. Khirade ${ }^{4}$ \\ ${ }^{1}$ Milliya Arts, Science \& Management Science College, Beed, India - syedsb@rediffmail.com \\ ${ }^{2}$ New Arts, Commerce \& Science College, Ahmadnagar, India - mudassarshaikh333@gmail.com \\ ${ }^{3}$ Shivaji College, Kannad, Dist. Aurangabad, India - kolhe_sb71@yahoo.com \\ ${ }^{4}$ Dr. Babasaheb Ambedkar Marathwada University, Aurangabad, India - pwkhirade59@gmail.com
}

\section{Commission V, SS: Emerging Trends in Remote Sensing}

KEY WORDS: Microwave, SAR, Geophysical Parameters, IEM Modelling.

\begin{abstract}
:
The microwave remote sensing is highly useful, as it provides synoptic observation of the Earth's surface or planetary bodies, regardless of day or night and the atmospheric conditions, propagation through ionosphere with minimum loss. One of the best microwave technology for imaging system is the Synthetic Aperture Radar (SAR) remote sensing. The microwave SAR currently represents the best approach for obtaining spatially distributed geophysical parameter present on the Earth's surface or planetary bodies. In the present work, geophysical parameters viz., Soil Moisture, Surface Roughness, Dielectric Constant $(\mathcal{E})$ and Backscattering Coefficients $\left(\sigma^{0}\right)$ will be retrieved. The modelling makes the process of estimating information beyond the real observation range for data interpretation. In the present paper most widely used modelling techniques for the microwave SAR dataset is an Integral Equation Model (IEM) which is implemented for above said geophysical parameters retrieval. The aim of the present work is to estimate accurate, reliable and skillful measurements of geophysical parameters from the microwave SAR dataset. In the present study microwave C band SAR dataset is used. The overall processing was done by using PolSARPro Ver. 5.0 software. In the present work, geophysical parameters are measured with the help IEM modelling, the statistical parameter and occurrence plane, estimated from the microwave SAR image, which was very helpful for retrieving geophysical parameters. From the overall paper work, it was concluded that the IEM modelling is a one of the realistic modelling methods for retrieving geophysical parameters for microwave C band SAR dataset.
\end{abstract}

\section{INTRODUCTION}

Microwave remote sensing is the study of the interaction of matter and electromagnetic radiation in the microwave region of the electromagnetic spectrum. The microwave Synthetic Aperture Radar (SAR) is the type of the remote sensing system, which acquired very high-resolution images of the Earth or planetary bodies. It has (Calla, 2009), the capacity to penetrate through clouds, fog, smoke, etc., though there is change in the conditions of the environment. It also has (Lillesand et. al., 2012), capability to sense the object on the Earth or planetary bodies during the day or night. The modelling makes the process of estimating information of the objects present on the Earth; beyond the original observation range which can be possible in the data interpretation. The land geophysical parameters like soil moisture, surface roughness, dielectric constant $(\varepsilon)$ and backscattering coefficients $\left(\sigma^{0}\right)$ etc. will be retrieved by using modelling techniques. Among these all the geophysical parameters the soil moisture is one of the important parameter. Since each object present on the Earth having $\sigma^{0}$, which can be vary depending upon the $\varepsilon$ and the soil moisture present at that time. Hence the radar backscatter $\sigma^{0}$ is very sensitive to soil moisture content and $\varepsilon$ of the object of Earth surface. Another important parameter called surface roughness, which is the disturbing factor that significantly affects the soil moisture measurement. In general, (Dong, 1997), it has been stated that backscatter is more sensitive to this factor than emission. The present study one of the widely used modelling technique for geophysical parameter retrieval called Integral Equation Model (IEM). These modelling is useful for the retrieving of the said geophysical parameters (Baghdadi, 2002; Shaikh et. al. 2018). The present modelling applied to microwave SAR image of microwave $\mathrm{C}$ band RADARSAT-2 SAR dataset. The dataset (MacDonald, 2016) is freely available on the MacDonald, Dettwiler and Associates (MDA) Ltd. The outcome from the dataset is analyze with the help of the statistical parameters like Mean, Median, Standard Deviation, Coefficient Variance and Equivalence Number of Look (ENL) and the occurrences plane. Based on these parameters the image accuracy is fixed and said geophysical parameters are retrieved. The overall processing on microwave dataset was done by using PolSARPro Ver. 5.0 software. This software provided by European Space Agency (ESA) open source toolbox for microwave SAR data processing and education. The software handles dual polarisation and full polarisation data from a wide range of microwave SAR space and airborne missions.

\footnotetext{
${ }^{*}$ Corresponding author
} 


\section{INTEGRAL EQUATION MODEL (IEM)}

The modelling makes the process of estimating, beyond the original observation range is possible in data interpretation. Let's consider the $\mathrm{V}$ output measurement as:

$$
V=f(u)+\varepsilon
$$

where $\varepsilon$ measurement error, $\mathrm{u}$ is geophysical variable and $\mathrm{f}$ is the remote sensing model.

The IEM is widely used in inversion procedures of microwave SAR images for retrieving geophysical parameters (Dubois, 1995). However, the parameter estimations require the use of a radar backscattering model that is capable of correctly modelling the radar signal (Gupta et. al. 2010). The microwave SAR image is converted from the provided format in the Digital Numbers (DN's) value, to the backscattering intensity information also known as the $\sigma^{\circ}$ :

$$
\sigma^{0}=10 X \log 10(D N)^{2}+C F
$$

where $\sigma^{\circ}$ is the backscattering intensity, represented in decibel units $(\mathrm{dB})$ and $\mathrm{CF}$ is the calibration factor for the data obtained, depending on the observation period and polarization. The $\varepsilon$ is a complex function with real and imaginary components, which have different soil texture in different land cover with varied moisture content have been expressed as,

$$
\varepsilon=\varepsilon^{\prime}-j \varepsilon^{\prime \prime}
$$

where $\mathrm{j}$ is the square root of -1 . The real part $\left(\varepsilon^{\prime}\right)$ is often expressed as the relative permittivity $\left(\varepsilon_{\mathrm{r}}\right)$. The imaginary part $\left(\varepsilon^{\prime \prime}\right)$ of the dielectric permittivity is usually expressed in terms of dielectric losses. The IEM reproduces radar backscattering coefficient (Baghdadi et. al. 2006). The IEM model proposed for rough surface scattering, which has been extensively applied to microwave remote sensing as:

$$
y(x)=g(x)+\int_{a}^{b} k(x, t) y(t) d t
$$

where, the function $g(x)$ and $k(x, t)$ is given and unknown function $y(t)$ is to be determined (Baghdadi et. al. 2010).

\section{RESULT AND DISCUSSION}

The microwave RADARSAT-2 SAR dataset initially was in SLC (Side Look Complex) format, therefore it has to be converted into the ground range using a multilooking process after importing the data into the PolSARPro software. The figure 1 shows the original quad pol $\mathrm{C}$ band RADARSAT-2 SAR image of Vancouver, Canada with latitude- $48^{0} 55^{\prime} 05.12^{\prime \prime} \mathrm{N}$ to $49^{0}$ $32^{\prime} 35.60^{\prime \prime} \mathrm{N}$ and longitude $122^{\circ} 46^{\prime} 13.52^{\prime \prime} \mathrm{W}$ to $123^{\circ}$ 21 ' 10.32 '' $\mathrm{W}$. The date of acquisition is $04 / 15 / 2008$ with 30 short pulse. After multilook processing, the data is filtered by Lee Refined speckle filter with $5 \times 5$ window size, because speckle noise degrades the quality of microwave SAR image.

Then decomposition parameters like entropy $(H)$, anisotropic $(A)$ and Alpha $(\alpha)$ images are generated using decomposition technique as shown in figure 2 (a), (b), (c) respectively.

(a)

(b)
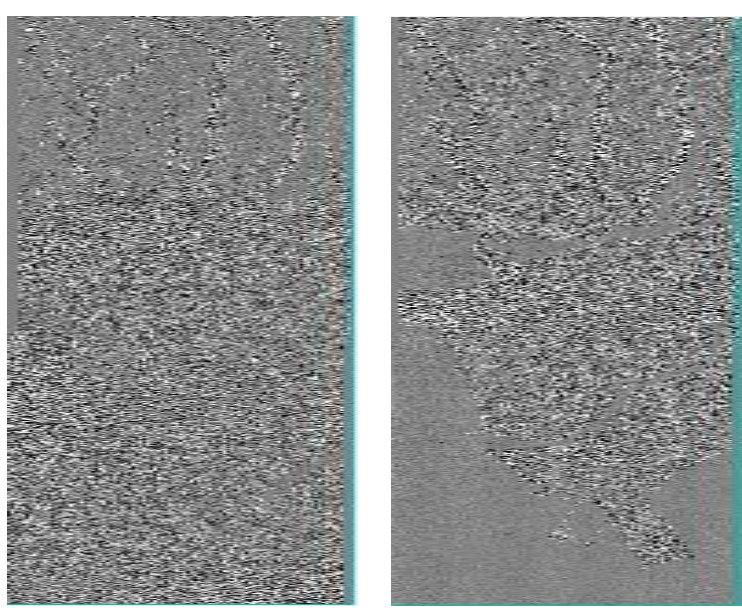

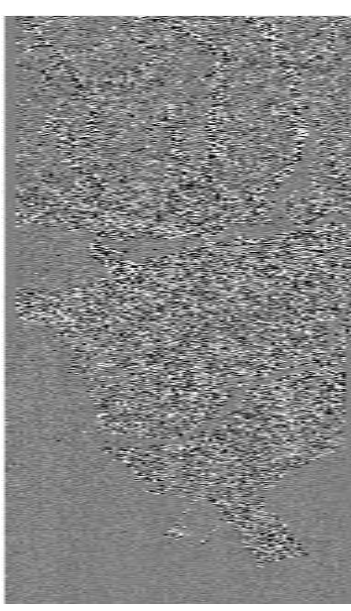

(c)

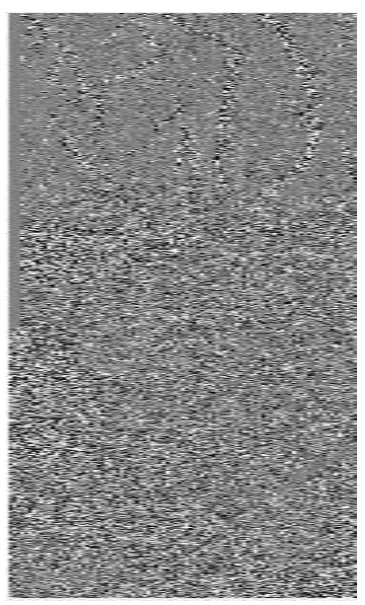

(d)

(a) $\mathrm{HH}$ (b) HV (c) VH (d) VV

Figure 1. Original quad pol RADARSAT-2 SAR image

Using H A Alpha parameters the Pauli RGB image and the H-A alpha classified image get as shown in figure 3 (a) and (b). The $\mathrm{H}$ A Alpha classified image shows the sixteen classes out of that the four-major class, viz., Water, Vegetation, Settlement and Terrain are studied. These results are further used for more detail finding of the geophysical parameters because each class has variation in the scattering effects.

(a)

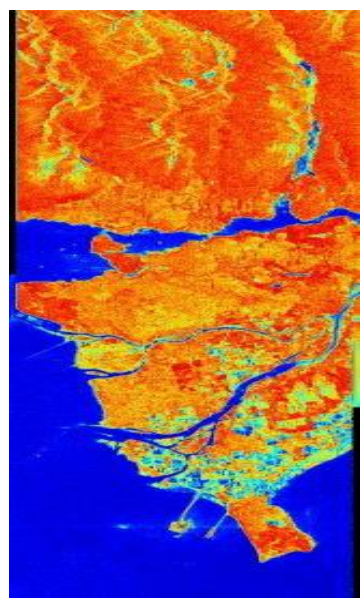

(b)

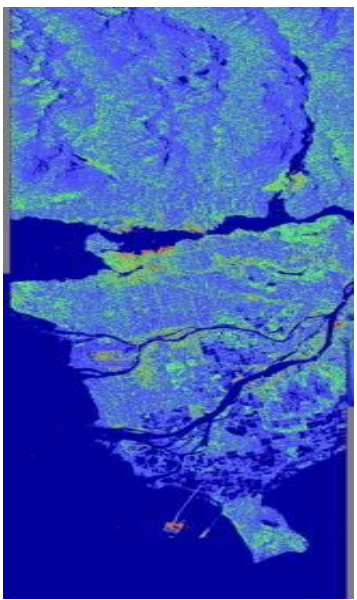




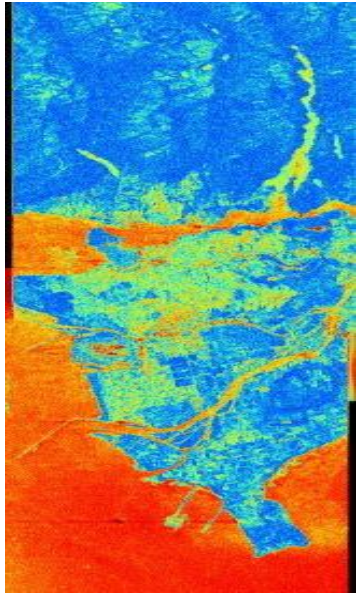

(c)

Figure 2. (a) Entropy (H) (b) Anisotropy (A) (c) Alpha ( $\alpha$ )image for Vancouver, Canada RADARSAT-2 SAR image

(a)

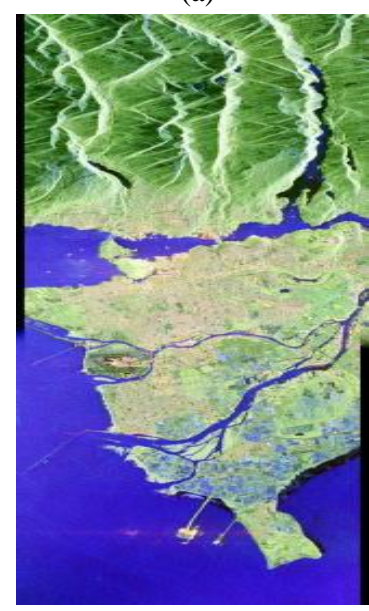

1. Water 2. Vegetation 3. Settlement 4. Terrain

Figure 3. (a) Pauli RGB image (b) H A Alpha classified image of Vancouver, Canada RADARSAT-2 SAR image

The statistical parameters of $\mathrm{H}$ A Alpha classified image is obtained from the each class DN's, which help to analyze geophysical parameters correctly. The table 1 shows these parameters as,

Table 1. Microwave RADARSAT-2 SAR statistical parameters

\begin{tabular}{|l|c|}
\hline \multicolumn{1}{|c|}{ Parameter } & H A Alpha classification \\
\hline Mean & 9.1718 \\
\hline Median & 10.9902 \\
\hline Standard deviation & 3.8417 \\
\hline Coefficient variation & 0.7249 \\
\hline ENL & 1.9029 \\
\hline
\end{tabular}

From the table 1, it is observed that the $\mathrm{H}$ A Alpha classified microwave SAR image has a less standard deviation i.e., 3.8417 and coefficient variance less than 1 i.e., 0.7249 , hence the less error in DN's further help to find more accurately retrieval of geophysical parameters.

Later, the IEM model applied on the classified image and from this the occurrence plane are generated, which gives the anisotropic information present in the image. The figure 4 shows occurrence plane for H A Alpha classified image.

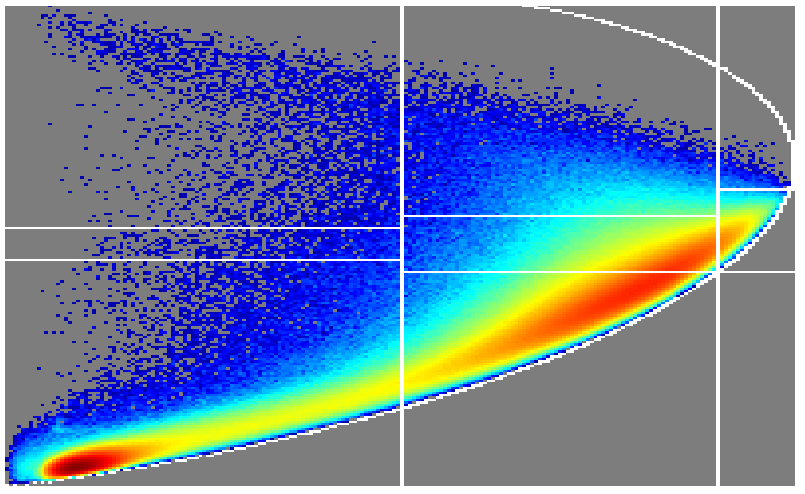

Figure 4. Occurrence plane for microwave RADARSAT-2 SAR $\mathrm{H}$ A Alpha classified image.

From the occurrence plane, it is observed that anisotropic particle present in $\mathrm{H} \mathrm{A}$ alpha classified image is high. This indicates that the more moisture level and high $\varepsilon$ value of the object present in the image. However, the dataset is microwave $\mathrm{C}$ band having a lower frequency 4 to $8 \mathrm{GHz}$ with the wavelength of $3.75 \mathrm{~cm}$ to $7.5 \mathrm{~cm}$ therefore the less $\sigma^{0}$ is occurred, and surface appeared as dark, which indicates the surface is smoother. The table 2 indicates that the $\sigma^{0}$ and $\varepsilon$ for approximate soil moisture level measured with the help of statistical parameters and occurrence plane obtained from the software tool.

Table 2. $\sigma^{0}$ and $\varepsilon$ for $\mathrm{H}$ A Alpha classified Vancouver, Canada RADARSAT-2 SAR image.

\begin{tabular}{|c|c|c|c|c|c|}
\hline Class & $\begin{array}{c}\text { Moist } \\
\text { ure } \\
\text { Level } \\
(\boldsymbol{\%})\end{array}$ & $\begin{array}{c}\text { Standar } \\
\mathbf{d} \\
\left(\mathbf{\sigma}^{\mathbf{0}}\right)\end{array}$ & $\begin{array}{c}\text { Observ } \\
\mathbf{e d} \\
\left(\mathbf{\sigma}^{\mathbf{0}}\right)\end{array}$ & $\begin{array}{c}\text { Standa } \\
\text { rd } \\
(\boldsymbol{\varepsilon})\end{array}$ & $\begin{array}{c}\text { Observ } \\
\text { ed } \\
(\boldsymbol{\varepsilon})\end{array}$ \\
\hline Water & 100 & $\begin{array}{c}-27.00 \\
\text { to }-28.00\end{array}$ & -27.835 & 80 & 78.238 \\
\hline $\begin{array}{c}\text { Veget } \\
\text { ation }\end{array}$ & $50-75$ & $\begin{array}{c}-12.00 \\
\text { to }-20.00\end{array}$ & -19.432 & $5<$ & 07.235 \\
\hline $\begin{array}{c}\text { Settle } \\
\text { ment }\end{array}$ & $20-40$ & $\begin{array}{c}01.00 \\
\text { to } 03.00\end{array}$ & 02.153 & $3-4$ & 03.568 \\
\hline $\begin{array}{c}\text { Terrai } \\
\mathrm{n}\end{array}$ & $50-75$ & $\begin{array}{c}-12.00 \\
\text { to }-20.00\end{array}$ & -18.257 & $5<$ & 06.951 \\
\hline
\end{tabular}

From the table 2, it is observed that both $\sigma^{0}$ and $\varepsilon$ parameters are found nearly same values compare with the standard values for the classes, viz., water, Vegetation, Settlement and Terrain. However the soil moisture is totally depends on the date and time of data retrieving. 


\section{CONCLUSION}

The present paper discussed about geophysical parameters retrieval of microwave $\mathrm{C}$ band SAR dataset using IEM modelling technique. The geophysical parameters; soil moisture, dielectric constant $(\varepsilon)$ and backscattering coefficients $\left(\sigma^{0}\right)$ has been retrieved successfully. From the classified microwave SAR dataset four major classes was under studied and it was found that more than $80 \%$ to $90 \%$ accuracy in the said geophysical parameters. The statistical parameters and occurrence plane was equally very helpful for retrieving geophysical parameters from microwave SAR dataset. Hence, from the overall paper work, it was concluded that the IEM modelling is a one of the realistic method for measurement of geophysical parameter of the Earth surface using microwave SAR dataset.

\section{REFERNCES}

Baghdadi, N., Holah, N., Zribi, M., 2006. Calibration of the Integral Equation Model for SAR data in C-band and $\mathrm{HH}$ and VV polarizations. International Journal Remote Sensing. 27, pp. $805-816$.

https://doi.org/10.1080/01431160500212278.

Baghdadi, N., Saba, E., Aubert, M., Zribi, M., Baup, F., 2011. Comparison between backscattered TerraSAR signals and simulations from the radar backscattering models IEM, Oh, and Dubois. IEEE Geoscience Remote Sensing Letter, 8, pp. $1160-1164$.

Baghdadi, N., King, C., Chanzy, A., Vigneron, J. P., 2002. An empirical calibration of IEM model based on SAR data and measurements of soil moisture and surface roughness over bare soils. International Journal of Remote Sensing. 23, pp. 4325-4340.

https://doi.org/10.1080/01431160110107671.

Calla, OPN., 2009. Microwave Remote Sensing. Director, DESIDOC, Metcalfe House: Delhi, pp. 1-25.

Dubois, P. C., Van Zyl, J. and Engman, T., 1995. Measuring Soil Moisture with Imaging Radars. IEEE Transactions on Geoscience and Remote Sensing. 33, pp. 915-926. doi.org/ 10.1109/36.406677.

Dong, Y., Forster, B., Ticehurst, C., 1997. Radar backscatter analysis for urban environments. International Journal of Remote Sensing, 18, pp.1351-1364. https://doi.org/10.1080/014311697218467.

Gupta, V. K. and Jangid, R. A., 2010. Estimation of Radar Backscattering Coefficient of Soil Surface with Moisture Content at Microwave Frequencies. International Journal of Pure and Applied Physics, 6(4), pp. 509-516. http://www.ripublication.com/ijpap.html.

Lillesand, Kiefer, Chipman. 2012. Remote sensing and image interpretation. ( $4^{\text {th }}$ Ed.). Wiley India Edition, pp. 470-574. MacDonald, Dettwiler and Associates (MDA) Ltd., RADARSAT-2 dataset 2016. Retrieved from http://gs.mdacorporation.com/SatelliteData/Radarsat2/ SampleDataset.aspx //.
Shaikh, M. A., Anpat, S. M., Khirade, P. W., Sayyad S. b. 2018. Microwave Spectroscopy Modelling for Geophysical Parameter Retrieval Using Synthetic Aperture Radar (SAR) Dataset. Indian Journal of Pure \& Applied Physics, 56 (IV), pp.311-314.

http://nopr.niscair.res.in/handle/123456789/44200. 